\title{
THE EFFECT OF MECHANICAL EXSUFFLATION ON RESPIRA- TORY GAS EXCHANGE IN CHRONIC PULMONARY EMPHYSEMA
}

\author{
By R. M. CHERNIACK 1 \\ (From Deer Lodge Veterans Hospital and the Department of Physiology and Medical Research \\ of The University of Manitoba, Winnipeg, Canada)
}

(Submitted for publication May 7, 1953; accepted July 30, 1953)

\section{INTRODUCTION}

An elevated arterial carbon dioxide tension is not infrequently found in patients with pulmonary emphysema. Donald and Christie (1) and Wilson, Borden, Ebert, and Wells (2) have shown that such patients are unable to lower their arterial $\mathrm{pCO}_{2}$ significantly by voluntary hyperventilation. This mechanical defect in the control of blood carbon dioxide tension makes these patients particularly susceptible to the development of respiratory acidosis. An associated event is a depression of the ventilatory response to increases of carbon dioxide tension so that anoxic stimulation of the carotid and aortic bodies becomes the prime stimulus for breathing (3). When oxygen therapy is instituted in an attempt to alleviate the anoxia, the obviously distressed cyanotic patient may become almost apneic, drowsy, and even comatose. This poses a difficult therapeutic problem.

The immediate object of the therapy in such patients is to provide an adequate lung ventilation which will overcome the anoxia and increase the elimination of carbon dioxide. Often some mechanical aid to respiration is urgently required. Electrophrenic respiration $(4,5)$ and mechanical respirators using intermittent positive pressure breathing applied to the upper airway (6) or as applied in the conventional tank respirator $(7,8)$ have been recommended as an adjunct to therapy in respiratory acidosis. As the exsufflator attachment to the tank respirator has been shown to effectively reverse disturbed alveolar gases resulting from obstructed breathing (9) it was of interest to determine its effect in pulmonary emphysema.

The purpose of this paper is to present the effect of the mechanical exsufflator on respiratory gas exchange in chronic pulmonary emphysema, to com-

1 Lecturer, Department of Physiology and Medical Research, The University of Manitoba, and Research Assistant, Deer Lodge Hospital, Deer Lodge, Manitoba. pare its effect to that of the conventional tank respirator, and to describe their combined use in the treatment of a severely ill emphysematous patient who developed respiratory acidosis.

\section{METHODS}

Mechanical exsufflation, devised as a means of eliminating bronchial secretions in patients with an ineffective cough $(10,11)$ is accomplished in a conventional tank respirator by producing a negative intratank pressure of $40 \mathrm{~mm}$. $\mathrm{Hg}$ for inflation of the lungs, and, by means of a swiftly opening butterfly valve, returning the intratank pressure to atmospheric in 0.06 second. Expiration therefore, in contrast to that in other forms of intermittent pressure breathing, is not impeded except for the initial 0.06 second. Expiratory volume flow rates measuring 60 per cent of the rates obtained during maximally vigorous coughs in normal subjects have been attained by this procedure (12).

In the present study the exsufflator was cycled 9 times a minute. The inspiratory pressure was built up over a 2 second period, thus allowing 4.6 seconds for expiration. The observations on the effect of the conventional tank respirator were made using an Emerson respirator cycled 17 times a minute with a pressure range of -20 to $+8 \mathrm{~cm}$. water, the time of inspiration and expiration being approximately equal. Each patient was instructed to 'breathe with' the apparatus being used.

Studies were made on 13 cases of chronic pulmonary emphysema in whom retention of carbon dioxide due to impaired pulmonary ventilation was suspected. In order to obtain a resting level all reclined in a conventional tank respirator for 30 minutes before any experiment was begun. The exsufflator was attached to the respirator so that either apparatus could be used and followed immediately by the other.

In order to determine the effect of these procedures and of the administration of oxygen, pulmonary ventilation was measured on a Benedict-Roth respirometer. Arterial blood samples were drawn by means of an indwelling Cournand needle and the Van Slyke-Neill technique was used for the determination of their oxygen content and capacity and carbon dioxide content (13). The arterial pH was determined by glass electrode at $37^{\circ} \mathrm{C}$. without exposure to air on a Beckman $\mathrm{pH}$ meter and the carbon dioxide tension was derived by the Henderson-Hasselbach equation. 


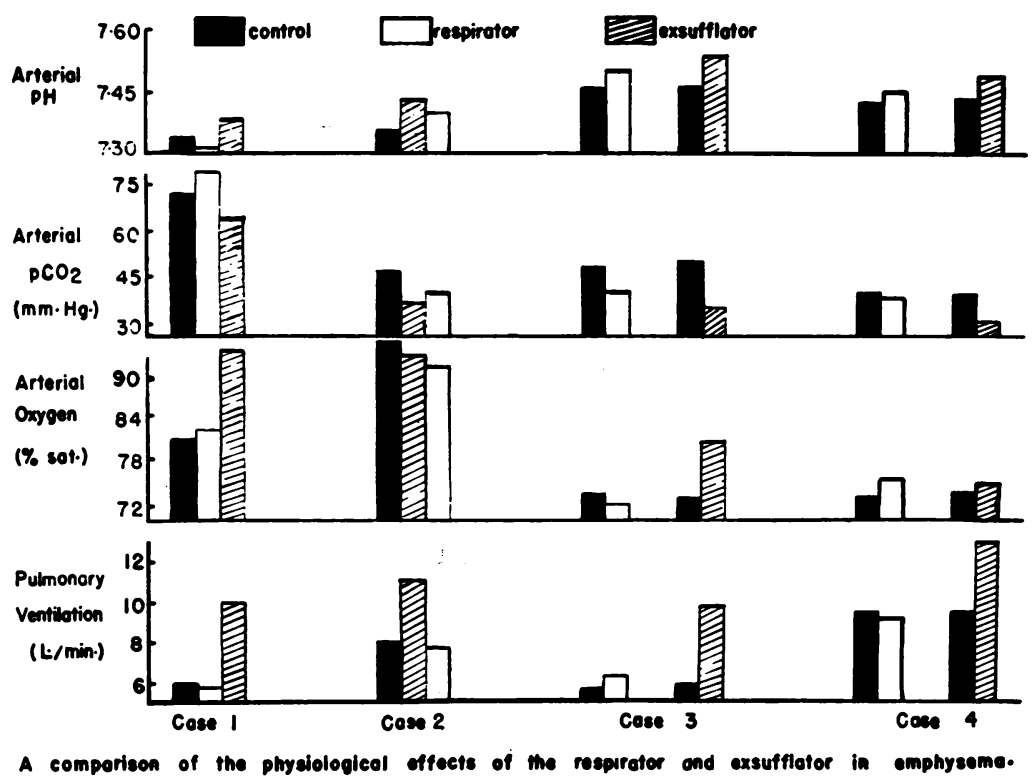

FIG. 1

RESULTS

In four patients with emphysema the effect of the exsufflator was compared to that of the conventional tank respirator. In Case 1, 30 minutes of exsufflation were followed immediately by $60 \mathrm{~min}$ utes of respirator treatment. This procedure was reversed in Case 2 and broken into two parts in Cases 3 and 4, the patients receiving exsufflation for 30 minutes one day and respirator treatment for 60 minutes the next.

The effect of these two procedures on minute volume, arterial $\mathrm{pH}$, carbon dioxide tension, and oxygen saturation is shown in Figure 1. The exsufflator resulted in an appreciable rise in $\mathrm{pH}$, a rise in $\mathrm{pH}$, a rise in oxygen saturation averaging 4.6 per cent and a fall in carbon dioxide tension averaging $10 \mathrm{~mm}$. $\mathrm{Hg}$ while the respirator produced only a slight effect on these measurements. It is seen that the minute ventilation was practically unchanged from the resting control level during respirator therapy while the exsufflator increased the average minute volume by 4 liters per minute or by 55 per cent. The tidal volume, unchanged by the respirator, was increased to three times that of the control when exsufflation was applied (Table I).

Respiratory acidosis was produced in eight patients with emphysema by the administration of 100 per cent oxygen by mask. Cases 5 and 6 re- ceived oxygen for 60 and 30 minutes, respectively, and were treated with the exsufflator immediately following cessation of oxygen therapy. The exsufflator was applied for 30 minutes in Case 5 and 15 minutes in Case 6 . Cases 7 to 12 received oxygen for 90 minutes and exsufflation for the last 30 minutes of administration.

In all eight cases oxygen caused a rise in arterial carbon dioxide tension and a fall in arterial $\mathrm{pH}$. Table II shows that in Cases 5 and 6 exsufflation promptly reversed these changes, the values being shifted towards normal. The reversal of acid-base disturbance when exsufflation was applied in Case 7 , despite the continued administration of 100 per cent oxygen is illustrated in Table III.

Determinations of ventilation and blood gases were also made two hours after the experiment in Cases 8 to 12 . Figure 2 shows that in three out of five cases the $\mathrm{pH}$ remained elevated and the $\mathrm{pCO}_{2}$ was maintained at a lower level two hours

TABLE I

The effect of the respirator and exsufflator on tidal volume

\begin{tabular}{cccc}
\hline \hline $\begin{array}{c}\text { Case } \\
\text { no. }\end{array}$ & $\begin{array}{c}\text { Control } \\
m l .\end{array}$ & $\begin{array}{c}\text { Respirator } \\
m l .\end{array}$ & $\begin{array}{c}\text { Exsufflator } \\
m l .\end{array}$ \\
\hline 1 & 360 & 312 & 1,133 \\
2 & 473 & 467 & 1,400 \\
3 & 312 & 369 & 1,075 \\
4 & 588 & 569 & 1,700 \\
\hline
\end{tabular}


after the period of exsufflation, but that the oxygen saturation fell to below the control value in four out of five cases.

The usefulness of the exsufflator in the treatment of a patient with severe emphysema who developed a marked respiratory acidosis was demonstrated in the following case :

Case 13 (.A. M.) - A 53 year old white man, was admitted to the hospital on July 5, 1952, complaining of severe dyspnea of seven months duration. He had been in good health until January, 1952, when he developed tightness in his chest, dyspnea and cough with expectoration of green sputum. Despite penicillin therapy these symptoms increased in severity and he required admission to hospital for a short time in February and again in March. He was found to have pulmonary emphysema with bronchopneumonia and possibly an early cor pulmonale. Vital capacity was 2.0 liters. He improved markedly when penicillin, aureomycin ard cligitalis were administered and phlebotomy performed and was discharged from hospital. On June 15, his dyspnea increased and by July 4, 1952, his symptoms had become very severe. He
TABLE II

The effect of exsufflation on acid-base disturbance produced by oxygen therapy in pulmonary emphysema

\begin{tabular}{|c|c|c|c|c|}
\hline \multirow[b]{2}{*}{$\begin{array}{l}\text { Case } \\
\text { no. }\end{array}$} & \multirow[b]{2}{*}{ State } & & \multicolumn{2}{|c|}{ Arterial } \\
\hline & & $\begin{array}{l}\text { Minute } \\
\text { colume } \\
\text { L. nin.) }\end{array}$ & nil & $\begin{array}{ll}\mathrm{WCO} \\
\mathrm{mm} \mathrm{I} \mathrm{g}\end{array}$ \\
\hline \multirow{3}{*}{5} & Rest & 7.65 & 7.38 & 46 \\
\hline & O. $60 \mathrm{~min}$. & 6.90 & 7.33 & 52 \\
\hline & Exsuff. $30 \mathrm{~min}$. & 9.90 & 7.42 & 39 \\
\hline \multirow{3}{*}{6} & Rest & 9.46 & 7.35 & 64 \\
\hline & $\mathrm{O}_{2} 30 \mathrm{~min}$. & 6.85 & 7.30 & 77 \\
\hline & Exsuff. $15 \mathrm{~min}$ & 12.74 & 7.36 & 57 \\
\hline
\end{tabular}

was then given continuous oxygen by mask at 6 to 7 liters per minute. Drowsiness was noted and he was taken to hospital.

On admission he was drowsy, cyanotic ard extremely dyspneic. The jugular veins were disterded. Chest was harrel-shaped and movement was limited bilaterally. Hyperresonance, distant breath sounds ard bilateral scattered ronchi were present. Blood pressure was $140 / 85$. The liver was palpable one and one-half finger breacths

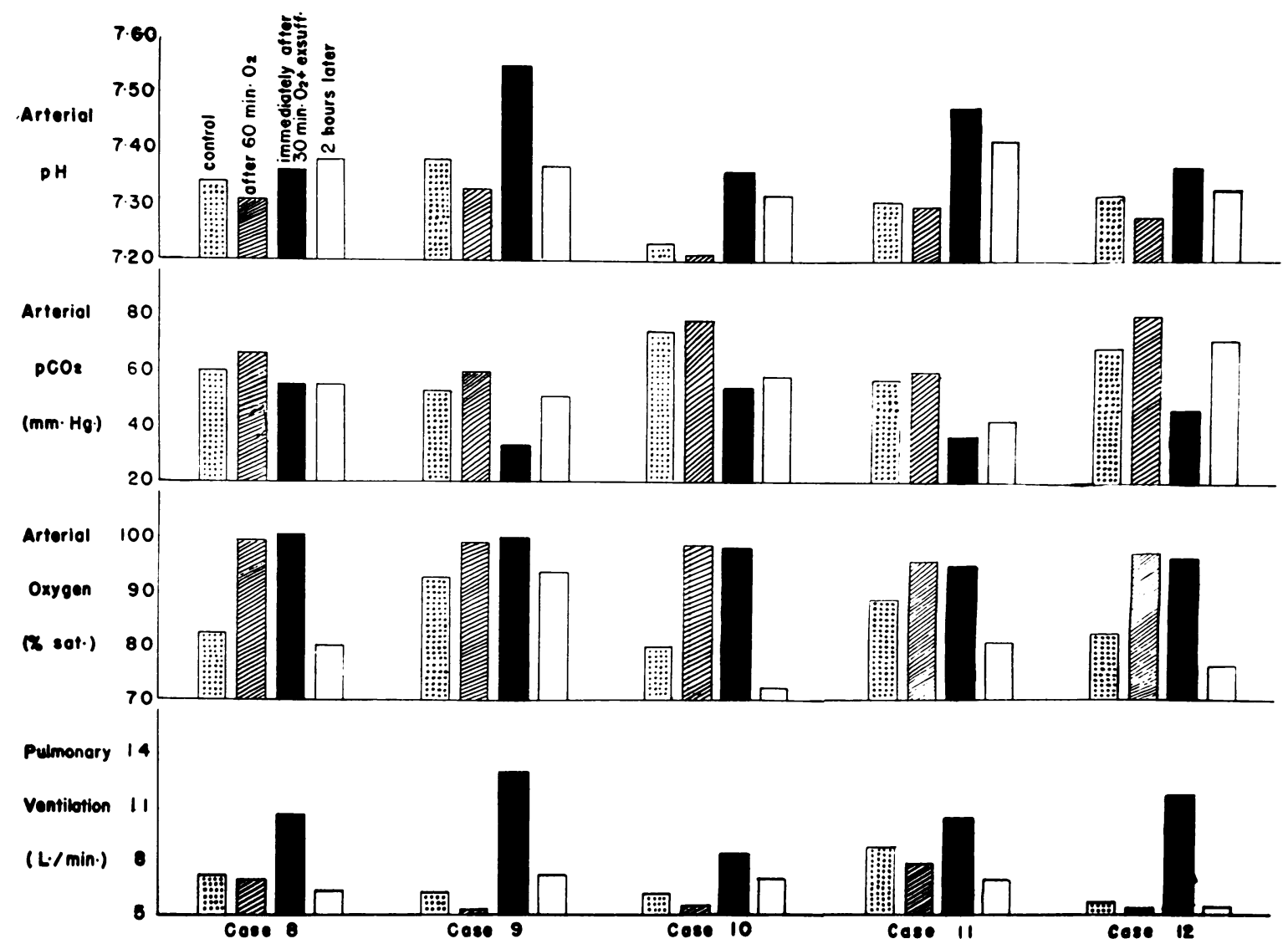

Fig. 2. Respiratory Gases before axd after Exsufflation ix Five Patients with Emphysema Made Acidotic WITH OXYGEN THERAPY 
TABLE III

The effect of exsufflation during continuous oxygen therapy in a patient with emphysema

\begin{tabular}{|c|c|c|c|c|}
\hline \multirow[b]{2}{*}{ State } & \multirow{2}{*}{$\begin{array}{c}\text { Minute } \\
\text { volume } \\
\text { (L./min.) }\end{array}$} & \multirow{2}{*}{$\begin{array}{c}\text { Oxygen } \\
\text { satura- } \\
\text { tion } \\
\% \\
\end{array}$} & \multicolumn{2}{|c|}{ Arterial } \\
\hline & & & $\mathrm{pH}$ & $\underset{(m m . H g}{\mathrm{pCO}_{2}}$ \\
\hline \multirow{4}{*}{$\begin{array}{l}\text { Resting } \\
\text { Oxygen } 60 \mathrm{~min} \text {. } \\
\text { Oxygen and } \\
\text { exsufflation }\end{array}$} & 6.8 & 92.8 & 7.44 & 44 \\
\hline & 5.9 & 98.1 & 7.36 & $5 \overline{5}$ \\
\hline & & & 742 & \\
\hline & 9.2 & 99.0 & 7.42 & 43 \\
\hline
\end{tabular}

below the costal margin. There was pitting edema of both ankles and slight clubbing of the fingers. Haemoglobin was $15.5 \mathrm{Gm}$. per cent; red blood cells, 7.8 million per cmm.; hematocrit, 55 per cent; and white blood cells, 11,600 per cmm. Vital capacity was 1.0 liters. The chest film revealed bullous emphysema with some right ventricular enlargement. EKG showed right axis deviation.

On July 7, further oxygen was administered and he became almost apneic. The arterial $\mathrm{pH}$ was 7.31 and the carbon dioxide tension $84 \mathrm{~mm}$. $\mathrm{Hg}$. He was placed in a tank respirator and also received exsufflation for $1 / 2$ hour every 2 hours. A comparison of the effect of the respirator and exsufflator on tidal volume and minute ventilation is shown in Table IV. He was treated by the combined use of the respirator and exsufflator and oxygen by nasal catheter at 1 to 3 liters per min. until July 10, 1952. The improvements in arterial $\mathrm{pH}$ and carbon dioxide tension are shown in Table V. By July 20th he was up and about though limited in activity, and discharged from hospital.

\section{DISCUSSION}

The results reported above indicate that the exsufflator is superior to the conventional respirator in managing the acid-base disturbance associated with respiratory acidosis in pulmonary emphysema. This might be explained by the ability of the exsufflator both to overcome obstruction to breathing (9) and to ventilate the alveoli more effectively.

The presence of bronchiolar obstruction due to either spasm or thick viscid secretions in the bronchi is probably a considerable factor in the development of anoxia and carbon dioxide retention in severe emphysema. The exsufflator has

TABLE IV

The effect of the respirator and exsufflator on tidal volume and minute ventilation (Case 13)

\begin{tabular}{lcc}
\hline \hline & $\begin{array}{c}\text { Tidal } \\
\text { volume } \\
(\text { ml. })\end{array}$ & $\begin{array}{c}\text { Minute } \\
\text { volume } \\
(\text { L. } / \text { min. })\end{array}$ \\
\hline Control & 286 & 5.2 \\
Respirator & 278 & 4.7 \\
Exsufflator & 645 & 5.8 \\
\hline
\end{tabular}

TABLE V

The effect of therapy on arterial blood estimations (Case 13)

\begin{tabular}{lccl}
\hline \hline & \multicolumn{2}{c}{ Arterial } & \\
\cline { 2 - 3 } \multicolumn{1}{c}{ Date } & $\mathrm{pH}$ & $\mathrm{pCO}_{2}$ & \multicolumn{1}{c}{ Comment } \\
\hline $7 / 7 / 52$ & 7.31 & 84 & Prior to therapy \\
$7 / 8 / 52$ & 7.43 & 67 \\
$7 / 9 / 52$ & 7.39 & 66 & During therapy \\
$7 / 11 / 52$ & 7.38 & 63 & Day after cessaţion \\
$7 / 15 / 52$ & 7.40 & 64 & $\begin{array}{c}\text { of therapy } \\
\text { Out of bed, limited } \\
\text { activity }\end{array}$
\end{tabular}

been shown to result in a marked elimination of secretions in many cases of emphysema (13). This effect could thus play a large role in the shift towards normal of the arterial blood gases and $\mathrm{pH}$.

In the cases treated in the conventional respirator the tidal volume and minute ventilation did not change appreciably from that present during unassisted respiration. However, a consistently marked increase in tidal volume occurred during the period of exsufflation. The increase in arterial oxygen saturation and fall in carbon dioxide tension despite a respiratory rate of only 9 times a minute is due to the threefold increase in tidal volume resulting in a more effective alveolar ventilation. Case 13 demonstrates that despite only a slight increase in minute ventilation, the marked increase in tidal air produced beneficial results.

No post-exsufflator period of apnea was observed despite the fact that the stimulus of anoxia was removed. It seems possible that the sensitivity of the respiratory mechanisms was at least partially restored by the changes in gas tension induced by the exsufflator. It is also noteworthy that in Cases 8, 10, and 11 the $\mathrm{O}_{2}$ saturation at two hours was below the original control level while the $\mathrm{CO}_{2}$ tension and $\mathrm{pH}$ were maintained at closer to normal values. This anomalous effect on arterial $\mathrm{O}_{2}$ and $\mathrm{CO}_{2}$ levels was presumably due to an increased ventilation of normal alveoli occurring at the expense of ventilation of malfunctioning parts of the lung.

It is concluded that exsufflation is a helpful adjunct in the handling of the problem presented by retention of carbon dioxide in a patient with severe pulmonary emphysema. During exsufflation, oxygen may be administered to such patients, thereby relieving the consequences of severe anoxia without inducing respiratory acidosis. However, as a 
sequel to the maintenance of a lowered arterial $\mathrm{pCO}_{2}$ the arterial blood may become more anoxic following cessation of therapy.

\section{SUMMARY}

In four cases of pulmonary emphysema, $30 \mathrm{~min}$ utes of therapy with the exsufflator resulted in an increased minute ventilation and beneficial effect on arterial $\mathrm{pH}$, carbon dioxide tension, and oxygen saturation. Respirator therapy for 60 minutes resulted in no appreciable change.

Uncompensated respiratory acidosis was produced in eight cases of emphysema by the administration of oxygen. The acid-base disturbance was effectively treated by a short period of exsufflation. In three of five cases the low level of $\mathrm{CO}_{2}$ was maintained after two hours while the oxygen saturation fell below the control level. The beneficial effect of the use of the exsufflator in the treatment of a patient with emphysema who developed respiratory acidosis was demonstrated.

The decisive increase in tidal air and minute ventilation with the rapid effect on pulmonary gas exchange during exsufflation appears to be a valuable adjunct to therapy in respiratory acidosis.

\section{ACKNOWLEDGMENTS}

The author desires to thank Dr. Alvan Barach for guidance and the use of the exsufflator and Dr. A. E. Thomson for valuable assistance. Some of the patients studied were investigated at the Goldwater Memorial Hospital, Columbia Division, and the Presbyterian Hospital, College of Physicians and Surgeons, New York. The majority of the work was performed under a Department of Veterans Affairs of Canada Research Grant held by Dr. J. Doupe.

\section{REFERENCES}

1. Donald, K. W., and Christie, R. V., The respiratory response to carbon dioxide and anoxia in emphysema. Clin. Sc., 1949, 8, 33.
2. Wilson, R. H., Bordën, C. W., Ebert, R. V., and Wells, $H$. S., A comparison of the effect of voluntary hyperventilation in normal persons, patients with pulmonary emphysema, and patients with cardiac disease. J. Lab. \& Clin. Med., 1950, 36, 119.

3. Scott, R. W., Observations on the pathologic physiology of chronic pulmonary emphysema. Arch. Int. Med., 1929, 26, 544.

4. Sarnoff, S. J., Hardenbergh, E., and Whittenberger, J. L., Electrophrenic respiration. Am. J. Physiol., 1948, 155, 1.

5. Sarnoff, S. J., in discussion of Comroe, J. H., Jr., Bahnson, E. R., and Coates, E. O., Jr., Mental changes occurring in chronically anoxemic patients during oxygen therapy. J. A. M. A., 1950, 143, 1044.

6. Motley, H. L., The use of oxygen in comatose states. Bull. New York Acad. Med., 1950, 26, 479.

7. Boutourline-Young, H. J., and Whittenberger, J. L., The use of artificial respiration in pulmonary emphysema accompanied by high carbon dioxide levels. J. Clin. Invest., 1951, 30, 838.

8. Stone, D. J., Schwartz, A., Newman, W., Feltman, J. A., and Lovelock, F. J., Precipitation by pulmonary infection of acute anoxia, cardiac failure and respiratory acidosis in chronic pulmonary disease. Am. J. Med., 1953, 14, 14.

9. Cherniack, R. M., Gordon, C. A., and Drimmer, F., Physiological effects of mechanical exsufflation on experimental obstructive breathing in human subjects. J. Clin. Invest., 1952, 31, 1028.

10. Barach, A. L., Beck, G. J., Bickerman, H. A., and Seanor, H. E., Mechanical coughing: Studies on physical methods producing high velocity flow rates during the expiratory cycle. Tr. A. Am. Physicians, 1951, 64, 360 .

11. Barach, A. L., Beck, G. J., Bickerman, H. A., and Seanor, H. E., Physical methods simulating cough mechanisms. Use in poliomyelitis, bronchial asthma, pulmonary emphysema, and bronchiectasis. J. A. M. A., 1952, 150, 1380.

12. Barach, A. L., Beck, G. J., Bickerman, H. A., and Seanor, H. E., Physical methods simulating mechanisms of the human cough. J. Appl. Physiol., 1952, 5,85 .

13. Van Slyke, D. D., and Neill, J. M., The determination of gases in blood and other solutions by vacuum extraction and manometric measurement. J. Biol. Chem., 1924, 61, 523. 